\title{
FRUTOS DE MELÃO SUBMETIDOS A PRÉ-TRATAMENTOS COM HIDROCOLÓIDES: EFEITOS DO PROCESSO DE CONGELAMENTO SOBRE A MICROESTRUTURA CELULAR ${ }^{1}$
}

\author{
Jaime V. RESENDE² e José CAL-VIDAL ${ }^{3, *}$
}

\begin{abstract}
RESUMO
Neste trabalho, o uso de hidrocolóides constituídos de pectina (1\%), carboximetilcelulose (CMC 0.5\%) e amido gelatinizado (5\%) adicionados ou não de sacarose $(15 \%)$ e nitrato de cálcio $(0.5 \%)$ foi testado com o objetivo de se avaliar a influência destes sistemas sobre os parâmetros de qualidade de melōes congelados com diferentes velocidades de resfriamento. Foram avaliados parâmetros tais como sólidos solúveis totais, perda de fluido celular por exsudação e capacidade de retenção de água após o descongelamento. As rupturas do tecido causadas pelo crescimento de cristais de gelo foram visualizadas por fotomicrografias obtidas por microscopia ótica e as disposições dos sistemas de hidrocolóides junto a parede celular puderam ser analisadas por microscopia eletrônica de varredura (SEM) do material congelado e liofilizado. Os parâmetros avaliados e as análises microscópicas da estrutura celular permitiram estabelecer alguns efeitos interativos entre os sistemas de hidrocolóides e a parede celular, responsáveis pela obtenção de estruturas menos danificadas. Estudos histológicos por microscopia ótica permitiram verificar os efeitos das interações sobre a resistência da parede ao rompimento celular. Os tratamentos com sistemas constituídos de amido gelatinizado e pectina, adicionados de sacarose e íons cálcio foram os que apresentaram os melhores resultados na manutenção da estrutura, menor perda de fluido e melhor textura do material descongelado. Os tratamentos com cálcio foram os principais responsáveis pela manutenção da firmeza dos frutos.

Palavras-chave: alimentos congelados; qualidade; microestrutura.
\end{abstract}

\section{SUMMARY}

PRETREATMENT OF MELONS WITH HYDROCOLLOIDS: EFFECT OF THE FREEZING PROCESS ON THE CELL MICROSTRUCTURES. In this research, the use of hydrocolloid constituted of pectin (1\%), carboxymethylcellulose (CMC) $(0.5 \%)$ and gelatinized starch (5\%), added to sucrose (15\%), was tested to evaluate the influence of these compounds on the quality parameters of frozen melons under various cooling rates. The evaluation parameters were soluble solids, loss of cellular fluid by exsudation and water holding capacity after thawing. Tissue disruption due to ice crystal growth was determined by optical microscopy and the physical distribution of gels on the cell wall was examined by Scanning Electron Microscopy (SEM) on frozen and freeze-dried materials. Evaluation parameters and microscopic analyses of cellular structure, permitted to detect the existence of interactive effects between hydrocolloid systems and the cell wall, which appears responsible for less damaged fruit structures. In addition, histological studies by optical microscopy permitted the verification of a possible increase of the wall resistance. Treatments with pectin and gelatinized starch added of sucrose and calcium ions presented the best results in the maintenance of the structure, minor loss of cellular fluid and better texture of the material after thawing. The treatments with calcium appeared to be responsible for the maintenance of the fruit firmness.

Keywords: frozen foods; quality; microstructure.

\section{1 - INTRODUÇÃO}

O uso de soluções de açúcares, hidrocolóides, sais de cálcio e sódio, e, associações e misturas envolvendo estes produtos tem sido os tratamentos indicados como substâncias que aumentam a resistência da estrutura celular ao congelamento. Grande parte destes compostos atua interagindo com os componentes da parede celular ou reduzindo o crescimento de cristais de gelo, mantendo a integridade da microestrutura após o descongelamento.

O tipo e extensão do dano causado ao tecido são dependentes da localização e tamanho do cristal de gelo. Vários estudos histológicos foram feitos com a finalidade de visualizar e determinar a perda da qualidade microestrutural $[1,4,13]$, ou a utilização de tais substâncias como pré-tratamentos anterior ao processo de congelamento $[8,9,17,18,19,20]$.

O início da cristalização da água no interior dos alimentos é determinado pela correlação entre temperatu-

1. Recebido para publicação em 07/08/2001. Aceito para publicação em 23/03/2002.

2. LEST/FEMEC/UFU - Av. João Naves de Ávila, 2600 - Bloco $1 \mathrm{M}$ Campus Santa Mônica - CEP 384000-089. Uberlândia/MG. E-mail. juresende@mecanica.ufu.br.

LAMIAA/DCA/UFLA - Cx. Postal 37 - CEP 37200-000 - Lauras/MG. * A quem a correspondência deve ser enviada. ra, velocidade de resfriamento, concentração de solutos e grandeza das forças que orientam as moléculas na fase líquida. Em sistemas biológicos a presença de membranas celulares interfere substancialmente no curso normal da cristalização da água no interior da microestrutura do alimento. O processo de crescimento do gelo a partir da água disponivel é complexo, e a viscosidade dos sistemas desempenha uma importante função neste processo [15, 16]. A rejeição do soluto, ou a adsorção seletiva na interface de crescimento são alguns fatores que podem estar envolvidos nestes mecanismos [15]. BLANSHARD \& FRANKS [2] têm proposto uma série de estratégias para o controle da cristalização da água em sistemas alimentares que incluem a inibição e o controle da nucleação, o controle do crescimento do cristal de gelo e a exploração do estado vítreo do alimento.

A extensão dos danos causados pelo crescimento de cristais de gelo pode ser avaliada através de medidas fisicas que relacionam a qualidade do produto com as características de composição, firmeza e porosidade do produto descongelado. Estes parâmetros incluem a perda de fluido celular por exsudação, sólidos solúveis totais, textura e capacidade de retenção de água pela microestrutura.

A perda de fluido celular está relacionada à exten- 
são das perfurações na parede celular causadas pelo crescimento de cristais de gelo durante o processo de congelamento. O teor de sólidos solúveis totais é um parâmetro que influencia diretamente as propriedades físico-químicas responsáveis pela cristalização inicial do gelo tais como ponto de congelamento, grau de superresfriamento, nucleação e crescimento de cristais de gelo [2]. A obtenção de parâmetros texturométricos após o descongelamento também permite avaliar o grau de ruptura do tecido de frutos causados pelo crescimento de cristais de gelo e assim verificar entre os diferentes pré-tratamentos, qual aquele se mostrou mais efetivo na manutenção das caracteristicas microestruturais [12]. A determinação de um indice de medida da capacidade de retenção de água pelas células é uma técnica que permite se ter uma idealização dos aspectos microestruturais do fruto descongelado quanto à porosidade, cavidades deixadas por cristais de gelo após o descongelamento e influência da adição de géis sobre a rede microestrutural formada após o descongelamento [6].

As análises microscópicas, ótica e eletrônica, permitem visualizar a integridade da microestrutura celular após o descongelamento. Entre as técnicas de microscopia ótica, a técnica de fixação a frio do material congelado tem sido recomendada. A fixação isotérmica a frio preserva as estruturas e retêm as relações de conformação da fase gelo em equilibrio termodinâmico com o material congelado. Esta condição é conseguida com uma solução fixativa com um ponto de fusão à temperatura de fixação (que é a temperatura na qual o material foi congelado) e a manutenção destas condições durante o periodo de fixação. Estas formulações interagem com os componentes do material conferindo rigidez à matriz e assegurando que o modelo do gelo seja preservado $[11,14]$. Para as análises em microscópio eletrônico de varredura (MEV) de tecidos congelados, as técnicas usuais de preparação têm sido a fixação a frio ou a liofilização [3].

Este trabalho teve como objetivos avaliar a influência do uso de substâncias conhecidas que inibem o crescimento de cristais de gelo aplicados a frutos de melão anterior ao congelamento e sua capacidade de reduzir os danos mecânicos causados pelo crescimento de cristais de gelo durante o processo de congelamento. Verificar a relação entre parâmetros de qualidade medidos após o descongelamento com o grau de ruptura na estrutura celular causada por cristais de gelo durante o congelamento. Identificar entre as substâncias testadas qual aquela se mostra mais efetiva na crioproteção da microestrutura celular. Avaliar o efeito individual e interativo dos principais fatores considerados e justificar os prováveis comportamentos e mecanismos responsáveis pela redução dos danos e manutenção da integridade da microestrutura celular. Visualizar os danos causados por cristais de gelo através de análises da microestrutura por microscopia ótica usando a técnica de fixação a frio, e eletrônica (MEV) do material congelado e liofilizado.

\section{2 - MATERIAL E MÉTODOS}

\section{1 - Preparo das amostras}

Discos de 3,0mm de espessura e 25,0mm de diâmetro de frutos de melões foram obtidos a partir das seções medianas de cilindros cortados perpendicularmente à direção axial de melões (Cocumis melo L. Inodorus) frescos obtidos no mercado local. Estes foram submetidos à infusão a vácuo em soluções de hidrocolóides constituídos de carboximetilcelulose (CMC) (0.5\%) (Labsynth), pectina (1.0\%) (SIGMA - teor de metoxilas 9,5\%) e amido gelatinizado (5.0\%) (Quimibrás), adicionados ou não de sacarose a $15 \%$ e nitrato de cálcio (ions $\mathrm{Ca}^{2+}$ ) a $0.5 \%$ durante um periodo de 6 horas. A proporção volume de fruto:volume de solução na infusão foi de 1:3 e cada procedimento foi realizado em triplicata.

\section{2 - Preparo das soluções de hidrocolóides usadas nos pré-tratamentos (infusão a vácuo)}

As soluções foram preparadas adicionando as substâncias formadoras de géis inicialmente em pequenas quantidades de água destilada e deionizada e misturadas até a homogeneização. Os demais componentes foram adicionados posteriormente, o volume aferido e a dissolução completa foi feita com o auxílio de um agitador magnético. Os sistemas constituídos de amido foram preparados suspendendo o amido em pequena quantidade de água destilada e deionizada fria. A gelatinização foi realizada aquecendo água até a temperatura de $80^{\circ} \mathrm{C}$, a partir de então a suspensão em água fria e os demais componentes foram adicionados sob agitação até a mistura turva se tornar transparente, sendo em seguida resfriada à temperatura ambiente.

\section{3 - Determinação do teor de sólidos solúveis totais}

O teor de sólidos solúveis totais (SST) das amostras foi avaliado em cada etapa do processo (in natura, após o pré-tratamento e após o congelamento) por leitura direta em refratômetro de bancada do tipo Abeé, utilizando suco do melão obtido após a filtração da polpa.

\section{4 - Determinação da textura}

A determinação da textura em cada etapa do experimento foi feita utilizando um penetrômetro com sonda $(1,11 \mathrm{~cm})$ aplicado na região central dos discos empilhados no interior de um suporte, com aberturas do mesmo diâmetro das amostras, feito para evitar que os discos das amostras empilhadas se desloquem durante a penetração da sonda. Os valores da resistência a penetração foram obtidos por leitura no aparelho.

\section{5 - Congelamento}

Após serem embalados, os cortes em forma de discos dos frutos fresco e pré-tratados, foram congelados seguindo três métodos de congelamento com o objetivo de se obter diferentes velocidades e temperaturas finais de congelamento: (1) congelamento em ar estático (AE) 
utilizando um freezer doméstico com temperatura do ar de $-20 \pm 2{ }^{\circ} \mathrm{C}$; (2) congelamento por imersão em pasta de dióxido de carbono sólido +etanol (IDC) $\left(0,7 \mathrm{~kg} \mathrm{CO}_{2} / 1\right.$ etanol) com temperatura do meio refrigerante de $-72 \pm 3^{\circ} \mathrm{C}$ e (3) congelamento por imersão em nitrogênio líquido (INL) $\mathrm{a}-196^{\circ} \mathrm{C}$.

\section{6 - Descongelamento}

O descongelamento é um parâmetro importante na manutenção da microestrutura e é desejável que seja o mais rápido possivel. O descongelamento foi feito colocando as embalagens de polietileno contendo as amostras em contato direto com a água de um banho termostático a $38 \pm 2{ }^{\circ} \mathrm{C}$ até as temperaturas dos centros térmicos serem superiores a $5^{\circ} \mathrm{C}$.

\section{7 - Análise da perda de fluido por exsudação (PF)}

A perda de suco ou fluido celular por exsudação foi avaliada como a perda de massa após o congelamento/ descongelamento e drenagem .

\section{8 - Determinação das propriedades de retenção de água}

Métodos comuns para medir propriedades de retenção de água em alimentos são baseados na aplicação de pressão, centrifugação, ou sucção por capilaridade de um material poroso em contato com a amostra. Neste trabalho foram feitas segundo o método descrito por FERRERO, MARTINO, ZARITZKY [6], adaptado para as condições experimentais, que é baseado na difusão do liquido no interior de um sistema capilar. As amostras descongeladas foram retiradas das embalagens e os diâmetros dos discos foram medidos usando um paquímetro e colocados sobre um papel de filtro. O tempo de contato entre a amostra e o papel de filtro foi de 1 minuto e o aumento da área úmida foi avaliado.

$I D=\left(\frac{D_{d}}{D_{0 d}}-\frac{D_{i}}{D_{0}}\right) \times 100$

onde $\mathrm{D}_{\mathrm{d}}$ é o diâmetro médio $(\mathrm{mm})$ das áreas úmidas produzidas pelas amostras congeladas com uma determinada velocidade de congelamento e descongeladas sob condições controladas; $\mathrm{D}_{\mathrm{Od}}$, é o diâmetro equivalente médio $(\mathrm{mm})$ das amostras após o descongelamento no tempo de contato inicial; $D_{i}$, é o diâmetro equivalente médio $(\mathrm{mm})$ da área úmida produzida pela amostra sem tratamentos; $\mathrm{D}_{0}$, diâmetro equivalente $(\mathrm{mm})$ no tempo de contato inicial da amostra sem pré-tratamento.

\section{9 - Microscopia ótica}

Imediatamente após o congelamento, amostras cúbicas de $5.0 \mathrm{~mm}$ de arestas, cortadas a partir dos discos foram colocadas em uma solução fixativa (álcool etílico absoluto:formaldeído 38\%:água, 45:10:45) pré-resfriada a $-20^{\circ} \mathrm{C}$ (freeze-fixation). Uma vez fixadas, a desidratação das amostras foi realizada a temperatura ambiente com uma série de concentrações de etanol aumentando gradualmente de $70 \%$ a absoluto. As etapas seguintes constituiram-se de parafinização, iniciada com aumento de concentrações graduais de xileno-alcool e parafina até o emblocamento final em parafina histológica. Os cortes foram feitos em micrótomo rotativo com seções de $13 \mu \mathrm{m}$, corados com fucsina básica e fotografados em um microscópio Olympus CBA-K com sistema para fotomicrografias PM6. A descrição detalhada de todo o procedimento contendo cada etapa, concentrações, temperatura e tempo de permanência em cada passo do processo pode ser encontrada em RESENDE [18].

\subsection{0 - Microscopia eletrônica}

Imediatamente após o processo de congelamento, as amostras submetidas a pré-tratamentos e provenientes dos três métodos de congelamento foram armazenadas em nitrogênio líquido até o momento da liofilização, após o que foram embaladas e armazenadas a vácuo em dessecadores contendo sílica-gel. Após a remoção do dessecador, as amostras foram recobertas com carbono e ouro em um evaporador a vácuo (JEOL, JEE-4X/5B) com vácuo de $10^{-5}$ Torr e visualizadas em um Microscópio Eletrônico de Varredura (JEOL, JSM 35C) a uma tensão de aceleração de $20 \mathrm{kv}$.

\subsection{1 - Análise estatística}

O experimento foi montado seguindo uma estrutura fatorial com quatro fatores em um delineamento inteiramente casualizado mostrados na Tabela 1. Todos os experimentos foram realizados em triplicata. Um teste para verificar a normalidade dos erros foi aplicado a todos os parâmetros, e, os dados foram analisados usando o pacote Sistema de Analises Estatísticas (SANEST-IAC). A significância das variações nos tipos e niveis dos fatores foi determinada usando análise de variância e um teste de média, o teste de Duncan foi usado para determinar a significância das diferenças entre tratamentos.

TABELA 1. Fatores e níveis dos fatores usados no planejamento experimental.

\begin{tabular}{ll}
\hline \multicolumn{1}{c}{ FATORES } & \multicolumn{1}{c}{ NÍVEIS } \\
\hline 1. Hidrocolóides & 1. Pectina \\
& 2. CMC \\
& 3. Amido \\
2. Ausência de Hidrocolóides \\
1. Sacarose \\
3. Nitrato de cálcio & 2. Ausência de sacarose \\
4. Velocidade de Congelamento & 2. Autrato de Cálcio \\
& 1. Lento (AE) Nitrato de Cálcio \\
& 2. Intermediário (IDC) \\
\hline
\end{tabular}

\section{3 - RESULTADOS E DISCUSSÃO}

\section{1 - Avaliação dos parâmetros de qualidade de fru- tos descongelados}

\subsection{1 - Perda de fluido celular após o descongela- mento}

Sistemas que envolveram a adição de géis de polis- 
sacarídeos, açúcar e sais de cálcio e suas interações produziram efeitos notáveis sobre a perda de fluido celular após o descongelamento atribuída a danos mecânicos causados à microestrutura pelo crescimento de cristais de gelo durante o congelamento. $\mathrm{O}$ teste de Fischer ( $\mathrm{Ta}$ bela 2) foi aplicado e os resultados mostraram que tratamentos com sistemas que envolvem a adição de sacarose, nitrato de $\mathrm{Ca}$ e os sistemas interativos gel + sacarose, gel + cálcio, sacarose + cálcio e a interação entre os três fatores gel + sacarose + cálcio produziram diferenças significativas quanto à perda de fluido celular por exsudação.

Como se pode observar pelo teste de médias da Tabela 3 considerando fixo o fator gel e a significância entre tratamentos, a natureza do gel não influenciou de forma distinta a perda de fluido após o descongelamento $(\mathrm{P}<0,01)$ e a presença de sacarose e nitrato de cálcio nos sistemas foi efetiva na redução da perda de fluido celular por exsudação $(\mathrm{P}<0,01)$.

TABELA 2. Análise de variância referente ao percentual de perda de fluido celular $(\% \mathrm{P} / \mathrm{P})$ após o descongelamento de frutos submetidos a pré-tratamentos com sistemas hidrocolóides + açúcar + íons cálcio sob diferentes condições de processamento.

\begin{tabular}{lccccc}
\hline \multicolumn{1}{c}{ Fontes } & $\mathrm{G}, \mathrm{L}$, & $\mathrm{S}, \mathrm{Q}$, & $\mathrm{Q}, \mathrm{M}$, & $\mathrm{F}$ & Signific, \\
\hline 1-Hidrocolóides & 3 & 224,9052 & 74,9684 & 2,5903 & $\mathrm{NS}$ \\
2 - Sacarose & 1 & 4486,5913 & 4486,5913 & 155,0204 & ${ }^{* *}$ \\
3 - Cálcio & 1 & 963,0221 & 963,0221 & 33,27427 & $* *$ \\
4- Vel, Cong, & 2 & 111,0313 & 55,5156 & 1,91817 & NS \\
5-Inter, $1 \times 2$ & 3 & 337,1384 & 112,3795 & 3,88293 & $*$ \\
6-Inter, $1 \times 3$ & 3 & 398,3907 & 132,7969 & 4,58839 & $*$ \\
7-Inter, $2 \times 3$ & 1 & 717,7156 & 717,7156 & 24,7984 & $* *$ \\
8-Inter, $1 \times 2 \times 3$ & 3 & 725,2548 & 241,7519 & 8,3530 & $*$ \\
9- Resíduo & 126 & 3646,6849 & 28,942 & & \\
\hline Total & 143 & 11610,7343 & & & \\
\hline
\end{tabular}

** Significativo pelo teste de Fisher ao nivel de $1 \%$ de probabilidade * Significativo pelo teste de Fisher ao nivel de $5 \%$ de probabilidade NS Não significativo pelo teste de Fisher ao nivel de $5 \%$ de probabilidade.

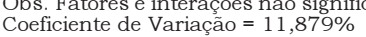

TABELA 3. Análise da percentagem média de perda de fluido celular $(\% \mathrm{P} / \mathrm{P})$ de frutos submetidos a pré-tratamentos com sistemas de hidrocolóides após o descongelamento considerando o efeito de três fatores do planejamento experimental.

\begin{tabular}{lcccc}
\hline \multicolumn{1}{c}{ Tratamento } & Repetições & Médias $^{1}$ & $5 \%$ & $1 \%$ \\
\hline CMC & 36 & 48,83 & a & A \\
Pectina & 36 & 47,81 & ab & A \\
Amido & 36 & 45,95 & $\mathrm{~b}$ & $\mathrm{~A}$ \\
Ausência de Hidrocolóide & 36 & 45,89 & $\mathrm{~b}$ & $\mathrm{~A}$ \\
Ausência de Sacarose & 72 & 49,71 & $\mathrm{a}$ & $\mathrm{A}$ \\
Sacarose 15\% & 72 & 44,54 & $\mathrm{~b}$ & $\mathrm{~B}$ \\
Ausência de Nit. de Cálcio & 72 & 49,71 & $\mathrm{a}$ & $\mathrm{A}$ \\
Nitrato de Cálcio 0,5\% & 72 & 44,54 & $\mathrm{~b}$ & $\mathrm{~B}$ \\
\hline
\end{tabular}

${ }^{1}$ Médias verticais seguidas por letras distintas diferem entre si ao nivel de significância indicado pelo teste de Duncan.

O efeito das interações entre os fatores estão mostrados na Tabela 4. Observa-se que a presença de sacarose e nitrato de cálcio são os fatores responsáveis pela redução da perda de fluido celular após o desconge- lamento sendo a redução maior quando ambos estão presentes (Tabela 4C). CMC, pectina e amido apresentam niveis de significância estatisticamente iguais quando estes fatores estão presentes, mas CMC e pectina apresentaram o maior percentual de perda de fluido celular quando na ausência de sacarose $(\mathrm{P}<0.01)$ e CMC e amido quando na ausência de nitrato de cálcio (Tabela 4 $A$ e $B$ ).

O efeito do cálcio pode ser atribuído à interação do cálcio com componentes da parede celular principalmente substâncias pécticas conferindo resistência e mantendo a integridade da estrutura celular durante o congelamento. Os efeitos da sacarose sobre a redução da perda de suco celular, podem ser justificados em termos de uma ligeira remoção de água do interior do fruto e um aumento no teor de sólidos resultantes da desidratação osmótica. Segundo GARROTE e BERTONE [9], a penetração dos solutos protege parcialmente os tecidos dos danos causados pelo crescimento de cristais de gelo durante o congelamento, conseqüentemente reduzindo a perda de fluido celular por exsudação.

TABELA 4. Análise da percentagem média de perda de fluido celular $(\% \mathrm{P} / \mathrm{P})$ por frutos após congelamento e pré-tratamentos com sistemas envolvendo os sistemas interativos entre os fatores.

\begin{tabular}{|c|c|c|c|c|c|c|c|c|c|}
\hline \multicolumn{10}{|c|}{ A) Efeito interativo Hidrocolóide versus Sacarose } \\
\hline \multicolumn{6}{|c|}{ Sacarose $15 \%$} & \multicolumn{4}{|c|}{ Sacarose $0 \%$} \\
\hline Trat. & Rep. & Médias $^{1}$ & $5 \%$ & $1 \%$ & Trat. & Rep. & Médias $^{1}$ & $5 \%$ & $1 \%$ \\
\hline Sem Hid. & 18 & 42,52 & a & A & CMC & 18 & 56,53 & $\mathrm{a}$ & A \\
\hline Pectina & 18 & 42,09 & a & A & Pectina & 18 & 53,53 & $a b$ & $A B$ \\
\hline CMC & 18 & 41,14 & a & A & Amido & 18 & 51,50 & $\mathrm{bc}$ & $A B$ \\
\hline Amido & 18 & 40,42 & a & A & Sem Hid & 18 & 49,27 & c & B \\
\hline \multicolumn{10}{|c|}{ B) Efeito interativo Hidrocolóide versus Nitrato de Cálcio } \\
\hline \multicolumn{6}{|c|}{ Nitrato de Cálcio 0,5\% } & \multicolumn{4}{|c|}{ Nitrato de Cálcio $0 \%$} \\
\hline Trat. & Rep. & Médias $^{1}$ & $5 \%$ & $1 \%$ & Trat. & Rep. & Médias $^{1}$ & $5 \%$ & $1 \%$ \\
\hline Sem Hid. & 18 & 46,01 & a & A & CMC & 18 & 51,65 & a & A \\
\hline $\mathrm{CMC}$ & 18 & 45,69 & a & A & Amido & 18 & 50,85 & a & $A B$ \\
\hline Pectina & 18 & 45,38 & a & A & Pectina & 18 & 50,24 & a & $A B$ \\
\hline Amido & 18 & 41,07 & b & A & Sem Hid & 18 & 46,15 & $\mathrm{~b}$ & B \\
\hline \multicolumn{10}{|c|}{ C) Efeito interativo Sacarose versus Nitrato de Cálcio } \\
\hline \multicolumn{6}{|c|}{ Nitrato de Cálcio 0,5\% } & \multicolumn{4}{|c|}{ Nitrato de Cálcio $0 \%$} \\
\hline Trat. & Rep. & Médias $^{1}$ & $5 \%$ & $1 \%$ & Trat. & Rep. & Médias $^{1}$ & $5 \%$ & $1 \%$ \\
\hline Sac. $0 \%$ & 36 & 52,35 & a & A & Sac. $0 \%$ & 36 & 53,06 & $\mathrm{a}$ & A \\
\hline Sac. $15 \%$ & 36 & 36,72 & b & B & Sac. $15 \%$ & 36 & 46,36 & b & B \\
\hline
\end{tabular}

${ }^{1}$ Médias verticais seguidas por letras distintas diferem entre si ao nivel de significância indicado pelo teste de Duncan.

\subsection{2 - Teor de sólidos solúveis totais (SST) do fruto após descongelamento}

A incorporação das substâncias usadas nos pré-tratamentos por infusão a vácuo teve uma influência distinta e significativa sobre este parâmetro (Tabela 5). Os efeitos são mais pronunciados em frutos tratados com sistemas géis e sacarose e sistemas interativos que envolvem os fatores géis sacarose, géis nitrato de cálcio e géis sacarose nitrato de cálcio $(\mathrm{P}<0.01)$, e a interação entre os fatores sacarose nitrato de cálcio $(\mathrm{P}<0.05)$. A Tabela 6 mostra que a natureza do gel formado produz 
resultados diferentes quanto ao teor de sólidos solúveis totais após o descongelamento.

TABELA 5. Análise de variância referente ao teor de sólidos solúveis totais (SST) ( $\left.{ }^{\circ} \mathrm{Brix}\right)$ após o descongelamento de frutos submetidos a pré-tratamentos com sistemas hidrocolóides + açúcar + íons cálcio sob diferentes condições de processamento.

\begin{tabular}{|c|c|c|c|c|c|}
\hline Fontes & $\mathrm{G}, \mathrm{L}$, & $S, Q$, & $\mathrm{Q}, \mathrm{M}$, & $\mathrm{F}$ & Signific, \\
\hline 1 -Hidrocolóides & 3 & 42,8870 & 14,2957 & 7,88441 & *夫 \\
\hline 2 - Sacarose & 1 & 484,1466 & 229,1466 & 126,3797 & *夫 \\
\hline 3 - Nit. de Cálcio & 1 & 2,7115 & 2,7115 & 1,4955 & NS \\
\hline 4 -Inter, $1 \times 2$ & 3 & 38,0065 & 12,6688 & 6,9871 & ** \\
\hline 5 -Inter, $1 \times 3$ & 3 & 88,2511 & 29,4171 & 16,22421 & ** \\
\hline 6 -Inter, $2 \times 3$ & 1 & 10.2827 & 10,2827 & 5,6712 & * \\
\hline $7-$ Inter, $1 \times 2 \times 3$ & 3 & 23,1142 & 7,7047 & 4,24932 & ** \\
\hline 8 - Resíduo & 128 & 232,0845 & 1,81316 & & \\
\hline Total & 143 & 1841 & & & \\
\hline
\end{tabular}

** Significativo pelo teste de Fisher ao nível de 1\% de probabilidade * Significativo pelo teste de Fisher ao nivel de $5 \%$ de probabilidade Obs. Fatores e interaçōes não significativas foram incorporados ao termo de resíduos. Obs. Fatores e interaçoes nao significat
Coeficiente de Variação $=18,797 \%$

TABELA 6 - Análise do teor de sólidos solúveis totais ( $\left.{ }^{\circ} \mathrm{Brix}\right)$ de frutos submetidos a pré-tratamentos com sistemas de hidrocolóides após o descongelamento considerando o efeito de dois fatores do planejamento experimental.

\begin{tabular}{lcccc}
\hline \multicolumn{1}{c}{ Tratamento } & Repetições & Médias $^{1}$ & $5 \%$ & $1 \%$ \\
\hline Amido & 36 & 8,38 & a & A \\
Ausência de Hidrocolóide & 36 & 8,11 & ab & AB \\
Pectina & 36 & 7,44 & bc & BC \\
CMC & 36 & 6,99 & $\mathrm{C}$ & $\mathrm{C}$ \\
Sacarose 15\% & 72 & 9,57 & $\mathrm{a}$ & $\mathrm{A}$ \\
Ausência de Sacarose & 72 & 5,90 & $\mathrm{~b}$ & $\mathrm{~B}$
\end{tabular}

${ }^{1}$ Médias verticais seguidas por letras distintas diferem entre si ao nivel de significância indicado pelo teste de Duncan.

Em sistemas onde a sacarose está presente, o gradiente de concentração existente entre o fruto e os componentes da solução, provoca aumento no teor de sólidos solúveis totais como resultado da incorporação de materiais por osmose à microestrutura do fruto ou nos espaços intercelulares devido ao processo de infusão a vácuo (Tabela $7 A)$.

A adição de cálcio por si só, não influencia o teor de SST após o descongelamento, mas os efeitos interativos apresentam resultados apreciáveis (Tabela $7 B$ e C). Podese observar que em tratamentos onde o fator sacarose não está presente o teor de SST é reduzido drasticamente.

\subsection{3 - Textura dos frutos após o descongelamento}

De acordo com os tratamentos dos dados experimentais, pode ser observado, que apenas os tratamentos onde os fatores sacarose e nitrato de cálcio estão presentes os resultados produzidos foram significativos (Tabela 8), ou seja influenciaram o valor da textura após o descongelamento $(\mathrm{P}<0.01)$.
A natureza do gel não influenciou sobre o valor final da resistência à penetração oferecida por frutos após prétratamento e congelamento. Os fatores que contribuíram para uma maior firmeza após o congelamento/descongelamento foram a incorporação de sacarose e nitrato de cálcio sendo este último atribuído como o principal responsável pela manutenção das propriedades texturométricas após o descongelamento. Este efeito é justificado tendo em vista a relação entre o cálcio e os componentes da parede celular [7, 8, 17].

TABELA 7. Análise do teor de sólidos solúveis totais ( $\left.{ }^{\circ} \mathrm{Brix}\right)$ de frutos submetidos a pré-tratamentos com sistemas envolvendo os sistemas interativos entre os fatores após o descongelamento.

\begin{tabular}{|c|c|c|c|c|c|c|c|c|c|}
\hline \multicolumn{10}{|c|}{ A) Efeito interativo Hidrocolóide versus Sacarose } \\
\hline \multicolumn{6}{|c|}{ Sacarose $15 \%$} & \multicolumn{4}{|c|}{ Sacarose $0 \%$} \\
\hline Trat. & Rep. & Médias $^{1}$ & $5 \%$ & $1 \%$ & Trat. & Rep. & Médias $^{1}$ & $5 \%$ & $1 \%$ \\
\hline Amido & 18 & 10,51 & a & A & Sem Hid & 18 & 7,12 & $a$ & A \\
\hline CMC & 18 & 9,33 & b & $A B$ & Amido & 18 & 6,25 & $a b$ & $A B$ \\
\hline Pectina & 18 & 9,32 & b & $A B$ & Pectina & 18 & 5,56 & bc & $\mathrm{BC}$ \\
\hline Sem Hid. & 18 & 9,10 & b & B & CMC & 18 & 4,66 & c & c \\
\hline \multicolumn{10}{|c|}{ B) Efeito interativo Hidrocolóide versus Nitrato de Cálcio } \\
\hline \multicolumn{6}{|c|}{ Nitrato de Cálcio 0,5\% } & \multicolumn{4}{|c|}{ Nitrato de Cálcio $0 \%$} \\
\hline Trat. & Rep. & Médias $^{1}$ & $5 \%$ & $1 \%$ & Trat. & Rep. & Médias $^{1}$ & $5 \%$ & $1 \%$ \\
\hline Amido & 18 & 8,35 & a & A & Sem Hid & 18 & 9,56 & a & A \\
\hline Pectina & 18 & 7,90 & a & $A B$ & Amido & 18 & 8,41 & b & A \\
\hline CMC & 18 & 7,46 & $a b$ & $A B$ & Pectina & 18 & 6,98 & c & B \\
\hline Sem Hid. & 18 & 6,66 & b & B & CMC & 18 & 6,53 & c & B \\
\hline \multicolumn{10}{|c|}{ C) Efeito interativo Sacarose versus Nitrato de Cálcio } \\
\hline \multicolumn{6}{|c|}{ Nitrato de Cálcio 0,5\% } & \multicolumn{4}{|c|}{ Nitrato de Cálcio 0\% } \\
\hline Trat. & Rep. & Médias $^{1}$ & $5 \%$ & $1 \%$ & Trat. & Rep. & Médias $^{1}$ & $5 \%$ & $1 \%$ \\
\hline Sac. 15\% & 36 & 9,70 & a & A & Sac.15\% & 36 & 9,43 & a & A \\
\hline Sac. $0 \%$ & 36 & 5,49 & b & B & Sac. $0 \%$ & 36 & 6,30 & b & B \\
\hline
\end{tabular}

${ }^{1}$ Médias verticais seguidas por letras distintas diferem entre si ao nivel de significância indicado pelo teste de Duncan.

TABELA 8. Análise de variância referente à variável textura (kg - sonda $\mathrm{D}=1,11 \mathrm{~cm}$ ) após o descongelamento de frutos submetidos a pré-tratamentos com sistemas hidrocolóides + açúcar + íns cálcio sob diferentes condições de processamento.

\begin{tabular}{lccccc}
\hline \multicolumn{1}{c}{ Fontes } & G,L, & S,Q, & Q,M, & F & Signific, \\
\hline 1 -Hidrocolóides & 3 & 1,0737 & 0,3579 & 0,6187 & NS \\
2 - Açúcar & 1 & 5,6446 & 5,6446 & 9,7579 & $* *$ \\
3 - Cálcio & 1 & 82,3859 & 82,3859 & 142,4210 & $* *$ \\
4 - Resíduo & 138 & 79,8285 & 0,5785 & & \\
\hline Total & 143 & 168,9327 & & & \\
\hline
\end{tabular}

** Significativo pelo teste de Fisher ao nivel de 1\% de probabilidade * Significativo pelo teste de Fisher ao nivel de $5 \%$ de probabilidade NS Não significativo pelo teste de Fisher ao nivel de $5 \%$ de probabilidade. Obs. Fatores e interações não significativas foram incorporados ao termo de resíduos. Coeficiente de Variação $=29,206 \%$

Os elementos das cadeias de polissacarídeos pécticos podem acondicionar-se de forma intermolecular em associação com o cálcio ou com outros cations para formar géis. O cálcio se fixa dentro de cavidades entre as cadeias ligando-se a grupos carboxilatos e a outros átomos de oxigênio eletronegativos que são ligantes favoráveis. A formação de géis de polissacarídeos pécticos re- 
sulta em textura mais firme e aumento da estabilidade das interligações entre os componentes da parede celular [10]. A contribuição da sacarose sobre o parâmetro textura é atribuída à remoção de água intracelular, inibindo o crescimento e diminuindo a quantidade de gelo formada responsável por danos mecânicos à estrutura celular. A Tabela 9 mostra os parâmetros estatísticos para a análise destas diferenças.

TABELA 9 - Análise do valor médio da resistência à penetração $(\mathrm{kg}$ - sonda $\mathrm{D}=1,11 \mathrm{~cm})$ de frutos submetidos a pré-tratamentos com sistemas envolvendo os sistemas interativos entre os fatores após o descongelamento.

\begin{tabular}{lcccc}
\multicolumn{1}{c}{ Tratamento } & Repetições & Médias $^{1}$ & $5 \%$ & $1 \%$ \\
Nitrato de cálcio 0,5\% & 72 & 3,34 & a & A \\
Nitrato de Cálcio 0\% & 72 & 1,82 & b & B \\
Sacarose $15 \%$ & 72 & 2,78 & a & A \\
Ausência de Sacarose & 72 & 2,39 & b & B
\end{tabular}

Médias verticais seguidas por letras distintas diferem entre si ao nivel de significância indicado pelo teste de Duncan.

\subsection{4 - Capacidade de retenção de água na microestrutura do fruto após o descongelamento}

O tratamento dos resultados experimentais obtidos da equação (1) mostra que (Tabela 10) os fatores géis sacarose e cálcio influenciam significativamente a velocidade com que o material libera água por difusão em um meio capilar $(\mathrm{P}<0,01)$, e, em um nivel mais baixo, a interação gel nitrato de cálcio também influencia os valores deste indice $(\mathrm{P}<0,05)$. A Tabela 11 mostra os testes de significância entre os tratamentos.

Considerando o fator gel como um fator fixo, podese verificar que a incorporação de géis reduz o valor do "ID" (Tabela 11). A presença do gel diminui a velocidade de escoamento do fluido após o descongelamento e a adição de nitrato de cálcio aumenta esta velocidade. Uma justificativa para estes resultados pode ser feita analisando os parâmetros responsáveis pelas condições com que a água está disponivel no sistema. As diferenças entre os ID's observados entre géis provavelmente são devidas às diferenças do caráter hidrofilico ou a afinidade com que o hidrocolóide se liga a água pura, ou seja, a força de hidratação.

A sacarose contribui interagindo com a água não ligada, diminuindo a mobilidade molecular da água e interferindo nos processos de interações interpoliméricas dos hidrocolóides. A adição de cálcio é favorável à formação de géis em sistemas constituídos de pectina aumentando a viscosidade, e, nos demais sistemas de polissacarídeos proporciona mais água ao sistema por competição com a água estrutural ligada às moléculas poliméricas (amido gelatinizado e CMC). O resultado é uma menor viscosidade, maior quantidade de água disponivel no sistema, maior formação de gelo durante o congelamento e menor capacidade de retenção de água após o descongelamento (Tabela 11).
TABELA 10. Análise de variância referente à capacidade de retenção de água avaliada através do índice de difusão do fluido celular (ID) após o descongelamento de frutos submetidos a pré-tratamentos com sistemas hidrocolóides + açúcar + íons cálcio sob diferentes condições de processamento.

\begin{tabular}{|c|c|c|c|c|c|}
\hline Fontes & $\mathrm{G}, \mathrm{L}$, & $\mathrm{S}, \mathrm{Q}$, & Q,M, & $\mathrm{F}$ & Signific, \\
\hline 1 -Hidrocolóides & 3 & 16519,9813 & 5506,6604 & 50,2347 & ** \\
\hline 2 - Sacarose & 1 & 7302,4224 & 7302,4224 & 66,6167 & ** \\
\hline 3 - Cálcio & 1 & 1356,9842 & 1356,9842 & 12,3792 & ** \\
\hline $4-$ Inter, $1 \times 3$ & 3 & 1171,9787 & 390,6596 & 3,5638 & * \\
\hline 5 - Resíduo & 135 & 14798,5063 & 109,6186 & & \\
\hline Total & 143 & 41149,8729 & & & \\
\hline
\end{tabular}

TABELA 11. Análise do índice médio de difusão do fluido celular por capilaridade (IDPF) de frutos submetidos a pré-tratamentos com sistemas de hidrocolóides após o descongelamento considerando o efeito de três fatores do planejamento experimental.

\begin{tabular}{lcccc}
\hline \multicolumn{1}{c}{ Tratamento } & Repetições & Médias $^{1}$ & $5 \%$ & $1 \%$ \\
\hline Ausência de Hidrocolóide & 36 & 43,15 & $\mathrm{a}$ & $\mathrm{A}$ \\
Amido & 36 & 23,97 & $\mathrm{~b}$ & $\mathrm{~B}$ \\
CMC & 36 & 17,07 & $\mathrm{C}$ & $\mathrm{C}$ \\
Pectina & 36 & 16,88 & $\mathrm{C}$ & $\mathrm{C}$ \\
Ausência de Sacarose & 72 & 32,39 & $\mathrm{a}$ & $\mathrm{A}$ \\
Sacarose 15\% & 72 & 18,15 & $\mathrm{~b}$ & $\mathrm{~B}$ \\
Ausência de Nit. de Cálcio & 72 & 28,34 & $\mathrm{a}$ & $\mathrm{A}$ \\
Nitrato de Cálcio 0,5\% & 72 & 22,20 & $\mathrm{~b}$ & $\mathrm{~B}$ \\
\hline
\end{tabular}

${ }^{1}$ Médias verticais seguidas por letras distintas diferem entre si ao nivel de significância indicado pelo teste de Duncan.

\section{2 - Análise microestrutural}

A Figura 1 (A) apresenta fotomicrografias obtidas por microscopia ótica do fruto fresco antes de ser submetido ao processo de pré-tratamento e congelamento. A Figura 1 (B) mostra detalhes dos espaços intercelulares encontrados em melões frescos onde supostamente os sistemas compostos de hidrocolóides e aditivos são inseridos durante a infusão a vácuo, e, a cristalização e crescimento dos cristais de gelo são iniciados.

\subsubsection{Danos mecânicos causados na estrutura celular pelo crescimento de cristais de gelo}

As análises dos frutos congelados e fixados a frio sem qualquer pré-tratamento mostraram um alto grau de ruptura da estrutura celular, principalmente para aqueles congelados em AE (Figura $2 A_{1}, B_{1}, C_{1}$ e $D_{1}$ ) e um maior número de estruturas integras, nos congelamentos feitos com IDC e INL, onde a velocidade de congelamento é mais rápida.

Quando os pedaços do fruto são submetidos à infusão a vácuo em soluções de baixa concentração, como no caso de soluções de nitrato de cálcio, ocorre a formação de um gradiente de concentração entre os compo- 
nentes celulares e a solução, induzindo a entrada de água no interior do fruto por osmose, aumentando o teor de água celular tornando a célula túrgida. Quando congelado, este fruto sofre severos danos porque o alto teor de água é favorável à formação de grandes cristais de gelo. O resultado destes tratamentos é a completa desintegração da estrutura celular (Figura $2 \mathrm{~A}$ e C).
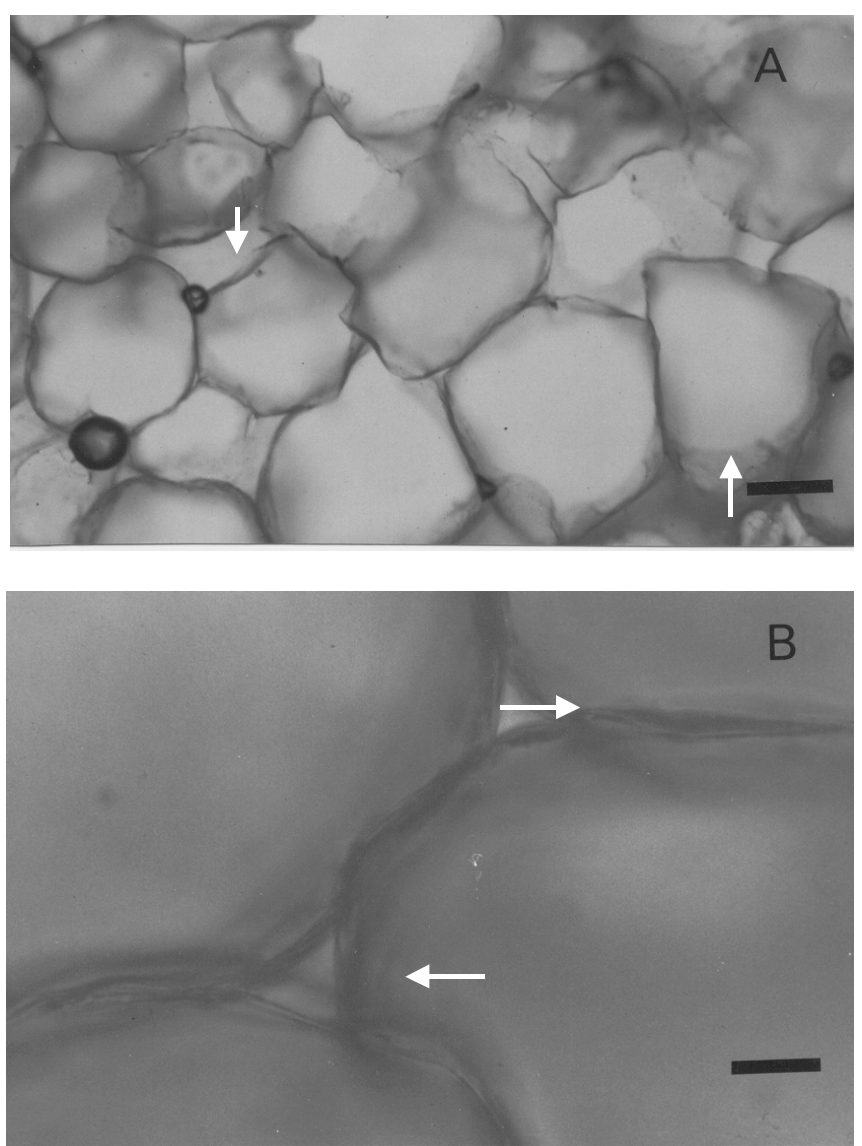

FIGURA 1. Fotomicrografias obtidas por microscopia ótica do fruto fresco antes de ser submetido aos processos de congelamento (A) mostrando a conformação da estrutura celular (barra $=80 \mathrm{~mm}$ ) e (B) mostrando em detalhe espaços intercelulares presentes na estrutura celular (barra $=20 \mathrm{~mm}$ )

Quando soluções de sacarose estão presentes no sistema, o gradiente de concentração atua no sentido inverso ao exposto na situação anterior. Ocorre uma remoção parcial da água intracelular e uma incorporação de materiais sólidos no interior do fruto.

Tratamentos realizados apenas com hidrocolóides não reduzem satisfatoriamente o grau de rompimento do tecido causado pelo crescimento de cristais de gelo (Figura 2A). A infusão de géis de baixa concentração promove a incorporação de água no sistema e sua capacidade de hidratação é pouco efetiva na retenção de água favorável ao crescimento de cristais de gelo.

A Figura 2 apresenta fotomicrografias de frutos tratados com sistemas constituidos de pectina submetidos aos três métodos de congelamento. Praticamente para todos os tratamentos com hidrocolóides, tal situação muda quando sacarose é adicionada aos sistemas (Figu- ra $2 B$ e $D$ ). A sacarose compete pela água de hidratação, remove parte da água intracelular e impede movimentos moleculares da água necessários ao crescimento dos cristais de gelo. Isto se deve a efeitos de microviscosidade além de uma provável interação na rede da estrutura molecular do hidrocolóide resultando em estruturas celulares mais integras e bem definidas.

Tratamentos hidrocolóides + sacarose + nitrato de cálcio resultam em estruturas ainda mais integras, principalmente aquelas processadas nos meios que proporcionam velocidades de congelamento mais rápidas. As fotomicrografias $\mathrm{D}_{1}, \mathrm{D}_{2}$ e $\mathrm{D}_{3}$ da Figura 2, mostram frutos tratados considerando os três fatores (pectina + sacarose + ions $\mathrm{Ca}^{2+}$ ). Os resultados obtidos são provavelmente devidos ao efeito interativo de três mecanismos: a retenção de água pela rede do gel, diminuição da mobilidade molecular pelo aumento da viscosidade a medida que a temperatura é abaixada, sendo tal efeito atribuido à presença da sacarose; e, a presença de ions $\mathrm{Ca}^{2+}$, aumentando a rigidez do gel além de uma possivel interação com componentes da parede celular; todos estes fatores contribuindo simultaneamente para uma redução na taxa de crescimento de cristais de gelo e uma resistência maior da parede celular aos danos mecânicos causados por estes cristais.

A Figura 2 também mostra que a velocidade de congelamento é reconhecida como um dos fatores responsáveis pela manutenção das características microestruturais do material congelado .

A comparação dos sistemas quanto a natureza dos hidrocolóides com o objetivo de se avaliar qual deles se mostra mais efetivo na preservação da microestrutura celular, mostrou que tratamentos feitos com pectina e amido gelatinizado como formadores de géis apresentaram melhores resultados. Estes tratamentos, sem considerar o método de congelamento, mostram estruturas integras com poucas rupturas de paredes celulares dando mais suporte a probabilidade da existência de um efeito interativo entre os diversos componentes dos sistemas fruto-crioprotetores.

\subsection{2 - Características microestruturais dos sis- temas de hidrocolóides junto a estrutura celular do fruto}

A Figura 3 apresenta fotomicrografias obtidas por microscopia eletrônica de varredura (MEV) de frutos congelados em AE e liofilizados, submetidos a pré-tratamentos com sistemas constituidos de CMC. As diferenças entre tratamentos podem ser caracterizadas pela porosidade, aderência às estruturas, estruturas amorfas, espessura, cavidades e conformação da rede.

Estruturas características obtidas por tratamentos específicos podem ser identificados nas fotomicrografias. Para pré-tratamentos com hidrocolóides adicionados de sacarose observa-se estruturas amorfas, compactas com pequenas cavidades e uma alta densidade da rede frutocrioprotetores (Figura 3 B e D). Estas estruturas são típicas da presença de sacarose que sofre colapso e se apresenta em um estado amorfo quando liofilizadas [5]. 

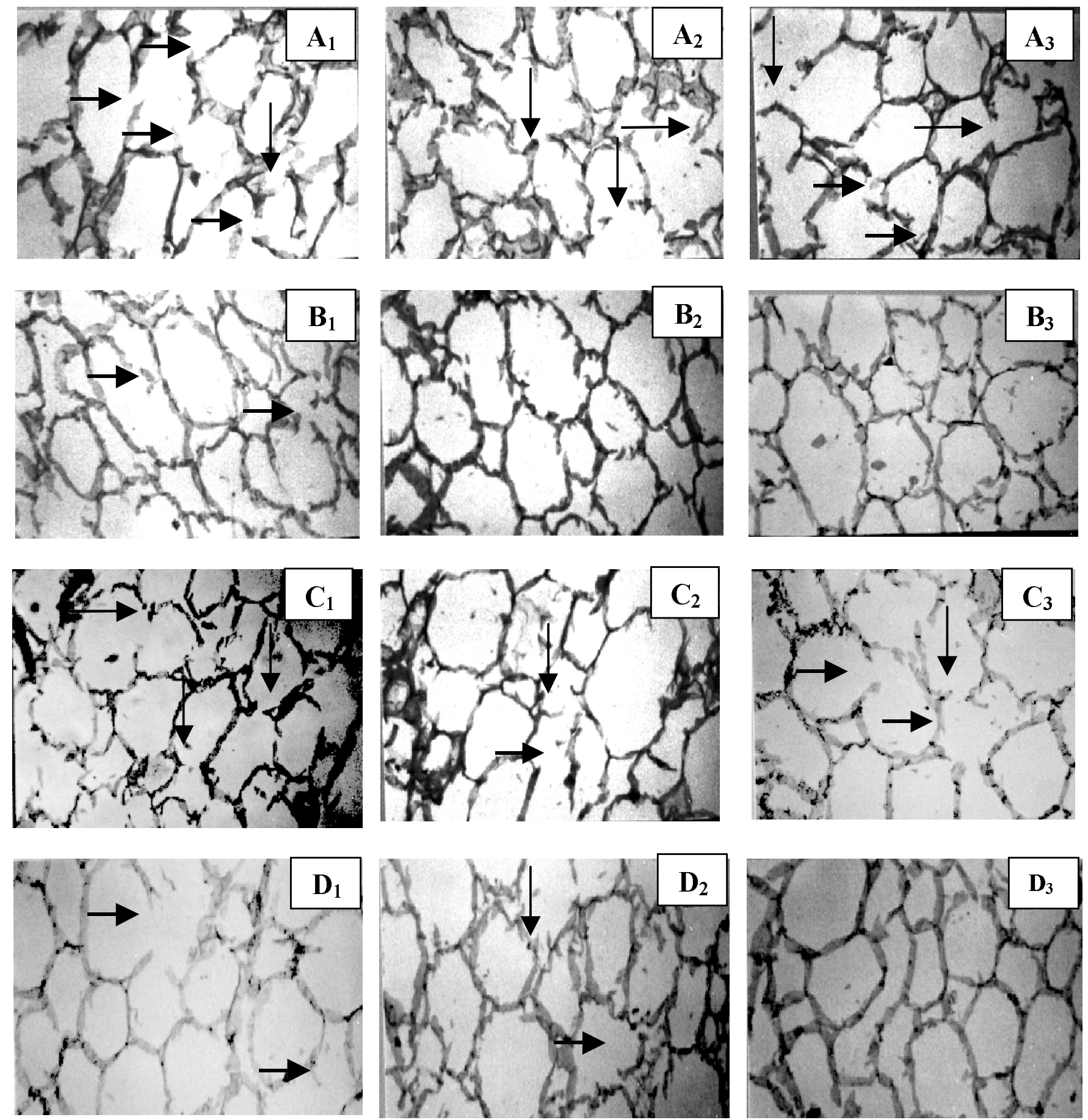

FIGURA 2. Fotomicrografias obtidas por microscopia ótica de frutos congelados submetidos a pré-tratamentos com sistemas constituídos de (A) Pectina 1\% e adicionados de (B) sacarose $15 \%$, (C) ions $\mathrm{Ca}^{2+}(0,5 \%)$ e (D) sacarose $15 \%+$ ions $\mathrm{Ca}{ }^{2+}(0,5 \%)$. Os subíndices referem-se a (1) congelamento em ar estático (AE), (2) congelamento por imersão em pasta de dióxido de carbono + etanol (IDC) e (3) congelamento por imersão em nitrogênio líquido. Detalhes mostram estruturas danificadas.

Frutos congelados submetidos a pré-tratamentos com hidrocolóides em presença de ions $\mathrm{Ca}^{2+}$ apresentam estruturas menos compactas, rigidas e com aspecto quebradiço (Figura 3 C). Estas estruturas apresentam enormes cavidades e uma baixa densidade da rede estrutural. Os aspectos de estruturas amorfas não são visiveis nestas estruturas.
Com os resultados obtidos, verifica-se que a incorporação do material é efetiva e modifica drasticamente os aspectos microestruturais dos sistemas frutocrioprotetores. Uma análise da porosidade da rede destes sistemas permite uma compatibilização com os resultados obtidos para os parâmetros medidos após o descongelamento como a perda de fluido por exsudação 

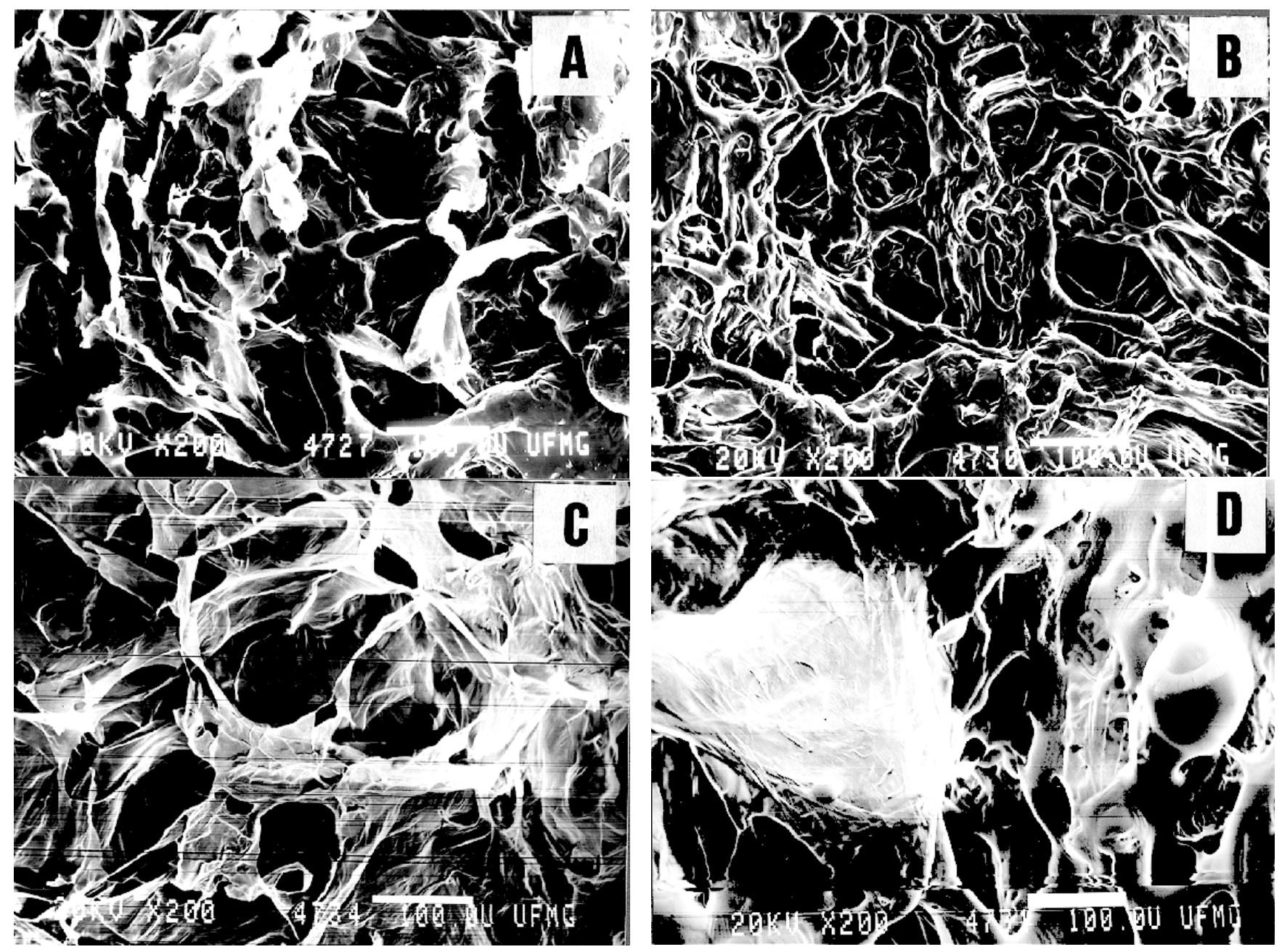

FIGURA 3. Fotomicrografias obtidas por microscopia eletrônica de varredura (SEM) após a liofilização de frutos congelados em ar estático (AE) submetidos a pré-tratamentos com sistemas constituídos de (A) Amido gelatinizado 5\%, (B) Pectina 1\% + sacarose 15\% mostrando a rede compacta e amorfa, (C) CMC 0,5\% + nitrato de cálcio mostrando o diâmetro da célula bem definido mas com grandes cavidades na estrutura resultante e (D) Amido 5\% + sacarose $15 \%+$ nitrato de cálcio $0,5 \%$ mostrando a microestrutura de uma célula praticamente íntegra (barra $=100 \mu \mathrm{m})$.

e a capacidade de retenção de água. Redes mais densas promovem uma menor perda de fluido por exsudação e uma maior capacidade de retenção de água.

Quanto à observação dos danos mecânicos causados à parede celular pelo crescimento de cristais de gelo por $\mathrm{MEV}$, o preparo de materiais utilizando a técnica da liofilização não é o melhor método. Quando a liofilização é utilizada como técnica de preparação, os solutos tais como os carboidratos solúveis são susceptiveis a colapso durante a liofilização destruindo os detalhes estruturais deixados pelos cristais de gelo [3]. Para o propósito de detectar a presença dos sistemas de crioprotetores junto a estrutura celular quanto a sua disposição e conformação, a técnica pode ser usada como um parâmetro de comparação.

\section{4 - CONCLUSÕES}

Os pré-tratamentos realizados apenas com sistemas de hidrocolóides não se mostraram efetivos na manu- tenção das características microestruturais do fruto de melão após o descongelamento.

A sacarose em concentração de $15 \%$ em sistemas de hidrocolóides protegeu o tecido de amostras congeladas, verificado pela redução na perda de fluido celular por exsudação e aumento na capacidade de retenção de água após o descongelamento. Amostras pré-tratadas com hidrocolóides em presença de sacarose resultaram em estruturas celulares mais integras, bem definidas e com paredes celulares pouco danificadas.

A presença de nitrato de cálcio em tratamentos com hidrocolóides foi vista como a principal responsável pela manutenção dos parâmetros texturométricos de amostras descongeladas.

Um efeito interativo envolvendo o sistema frutohidrocolóides-sacarose-cálcio foi verificado, observando a menor perda de fluido celular, maior teor de sólidos solúveis, textura superior e maior capacidade de 
retenção de água pela microestrutura após o descongelamento.

A interação também exerceu efeito na manutenção das características microestruturais verificadas pela maior integridade da estrutura celular, aumento da resistência da parede celular à ruptura causada pelo crescimento de cristais de gelo, paredes celulares mais bem definidas. Amostras que apresentaram estruturas compactas, amorfas, com uma alta densidade da rede frutocrioprotetores após congelamento e liofilização foram eficientes no aumento da resistência contra os danos causados pelo crescimento de cristais de gelo.

Dentre os hidrocolóides, sistemas constituídos por pectina $1 \%$ e amido gelatinizado $5 \%$ principalmente em presença de sacarose $15 \%$ e ions $\mathrm{Ca}^{2+} 0,5 \%$, foram os crioprotetores mais efetivos na manutenção das caracteristicas microestruturais do fruto de melão congelado.

\section{5 - REFERÊNCIAS BIBLIOGRÁFICAS}

[1] AHMED, E.;MIRZA, S.; ARREOLA, A.G. Ultratructural and textural changes in processed carrot tissue. Journal of Food Quality. v. 14, p. 321-30, 1991.

[2] BLANSHARD, J.M.; FRANKS, F. Ice crystallization and its control in frozen-food systems. In : BLANSHARD, J.M. \& LILFORD, P. (eds.). Food Structure and Behavior, London: Academic Press, Cap. 4, p. 51-65, 1987.

[3] BOMBEN, J.L.; KING, C.J. Heat and mass transport in the freezing of apple tissue. Journal of Food Technology. v. 17, p. 615-632, 1982.

[4] BROWN, M.S. Textural of Frozen Vegetables: Effect of freezing rate on green beans. Journal of the Science Food and Agriculture. v. 18, p. 77-81, 1967.

[5] CHINACHOTI, P.; STEINBERG, M.P. Interaction of sucrose with starch during dehidration as shown by water sorption. Journal of Food Science, v. 49, p. 1604-1608, 1984.

[6] FERRERO, C.; MARTINO, M.N.; ZARITZIKY, N.E. Effect of freezing rate and xanthan gum on the properties of com starch and wheat flour pastes. International Journal of Food Science and Technology, v. 28, p. 481-98, 1993.

[7] Fuster, C. PRestamo, G.; CANET, W. Effect of pretreatmemts and freezing on differentt strawberry varieties. In: IIR - Meeting, Sofia, Bulgária. Refrigeration Science. Technology, p. 350-5, 1982a.

[8] FUSTER, C.; PRESTAMO, G.; SPINOSA, J. Frozen apples slices: effect of different treatments and vacuum on the texture and color In: IIR - Meeting, Sofia, Bulgária. Refrigeraton Science Technology. p. 190-95, 1982b.

[9] GARROTE, R.L.; BERTONE, R. A. Osmotic concentration at low temperature of frozen strawberry halves. Effect of glicerol, glucose and sucrose solutions on exsudate loss during thawing. Lebensmittel-Wissenchalft un Technologies. v. 22, p. 264-267, 1989.

[10] HALL, M.A. Cell wall structure in relation to texture. In: GOODENOUGH, P. W.; ATKIN, R.K. (eds.) Quality in stored and processed vegetables and fruits, Bristol: Academic Press, 1979. p. 53-64.

[11] LAMPILA, L.E.; MOHR, V.; REID, D.S. Scanning Electron Microscopy study of rockfish preserved at either ambient temperature or by isothermal frezze-fixation. Food Microstructure, v. 4, p. 11-16, 1985.

[12] MAIN, G.L.; MORRIS, J.R.; WEHUNT, E.J. Effect of preprocessing treatments on the firmness and quality characteristics of whole and sliced strawberries after freezing and thermal processing. Journal of Food Science, v. 51, n. 2, p. 391-394, 1986.

[13] MARTI,J.; AGUILERA J. M. Efecto de la velocidad de congelación en las características mecánicas e microestructurales del arádano y de la mora silvestre. Rev. Agroquim. Tecnol. Aliment., v. 31, n. 4, p. 493503, 1991

[14] MARTINO, N. M.; ZARITZKY, N.E. Fixing conditions in freeze-substitution technique for light microscopy observation of frozen beef tissue. Food Microstructure, v. 5, p. 19-24, 1986.

[15] MUHR, A.H.; BLANSHARD, J.M.V. Effect of polysaccharide stabilizers on the rate growth of ice. Journal of Food Technology, v. 21, p. 683-710, 1986.

[16] MUHR, A.H.; BLANSHARD, J.M.V., SHEARD, S.J. Effect of polysaccharide stabilizers on the nucleation of ice. Journal of Food Technology, v. 21, p. 587-603, 1986.

[17] PAOLETTI, F.; MENESATTI, P. Effetto del pretrattamento com $\mathrm{Ca} 2+$ sulla texture di mele Golden Delicious congelate o osmodisidrate. Industrie Alimentari, n. 32, p. 34-41, ott. 1993.

[18] RESENDE, J.V. Redução de danos de congelamento em frutos utilizando substâncias crioprotetoras de concentrações e origens diversas. 1995, 146p. (Mestrado em ...). Universidade Federal de Lavras.

[19] RESENDE, J.V.; CAL-VIDAL, J. Reducing freezing damage in fruits. Engineering \& Food at ICEF 7. (supplement) Proc. Seventh international Congress on Engineering and Food, p. 1-4, 1997, Brighton, England.

[20] RESENDE, J.V.; GONÇALVES, R.A.; CAL-VIDAL, J. Avaliação dos efeitos da adição de crioprotetores como prétratamento sobre os parâmetros de qualidade de melões após o descongelamento. Actas del II Congreso Iberoamericano de Ingenieria de Alimentos. (CDROM), 1998, Bahia Blanca, Argentina.

\section{6 - AGRADECIMENTOS}

Ao CNPq pelo auxílio financeiro à pesquisa. Ao Professor Dr. Dagoberto Brandão Santos e Professora Dra Amazile Biagione R. de Abreu Maia (UFMG) pelas facilidades ao acesso a equipamentos necessários para a conclusão deste projeto. 